\title{
Corporate Strategy, Pay Gap and Employee Turnover Rate: Based on Mediation Model
}

\author{
Xiangyi Zhu \\ Business School, Shandong University of Technology, Zibo, China
}

Email address:

sdzbkm2003@126.com

To cite this article:

Xiangyi Zhu. Corporate Strategy, Pay Gap and Employee Turnover Rate: Based on Mediation Model. Science Journal of Applied Mathematics and Statistics. Vol. 9, No. 3, 2021, pp. 78-84. doi: 10.11648/j.sjams.20210903.12

Received: July 8, 2021; Accepted: July 19, 2021; Published: July 24, 2021

\begin{abstract}
The characteristics of prospector are to constantly find new market opportunities, carry out technological innovation, and obtain growth opportunities by moving to high value-added fields. Defender often choose a relatively stable market area and take effective actions, such as setting competitive prices or providing high-quality products and services, to actively prevent subsequent competitors from entering this industry. Although different strategic types of enterprises have different business preference, they cannot do without the active cooperation of employees in the process of strategy implementation, because they are the closest to the production and customers. If the incentive mechanism conflicts with employees' interests, employees may respond by leaving. Based on the sample of China's A-share listed companies from 2007 to 2019, this paper uses the fixed effect model to examine the impact of strategy on employee incentive mechanism and turnover rate. The empirical results show that, compared with defender, the pay gap of prospector is higher, and the above phenomenon is more significant in enterprises with lower labor intensity. In addition, prospector will also push up the turnover rate of employees, in which the pay gap plays a mediating role. This conclusion not only enriches the research of strategic theory and compensation contract, but also has some enlightenment for the relevant government departments to develop vocational training to improve employees' skills.
\end{abstract}

Keywords: Strategy, Pay Gap, Employee Turnover Rate

\section{Introduction}

As a microeconomic entity, enterprises are the main force in adjusting the industrial structure and economic growth mode in China. The success of enterprises cannot do without the correct decision-making of management and effective cooperation with employees. Compensation contract can guide the behavior of managers and employees. It is a governance tool for shareholders to influence management and employees to work in a way beneficial to shareholders. From a macro perspective, the enterprise compensation contract will also involve the reform of the equity and efficiency of dividend distribution, which has been an important issue of concern. The public and the media focus on the internal pay gap between the management and the employees, which is harmful to social justice. Pay distribution method should adapt to the enterprise's strategic positioning, based on the position value and contribution, the salary of key posts should have market competitiveness, and the pay gap should be reasonably widened. It can be seen that the phenomenon of higher pay gap can not only be attributed to the management's pursuit of personal utility maximization, but also may be the result of corporate strategic needs.

Previous studies have shown that strategy is the determinants of compensation contract, and the effectiveness of compensation contract depends on the characteristics of enterprise strategy $[1,2]$. A properly designed compensation contract can boost the process of achieving the strategic objectives of an enterprise, but if it cannot keep internal consistency with the overall strategy, the enterprise will lose its way. Employees in some key positions of enterprises usually have professional knowledge and skills, and control the resources or performance that are also crucial to the management. They must be given considerable discretion in their work, and it is difficult to use administrative management to limit. Employees have no motivation to implement the enterprise strategy that conflicts with their own interests. Improper design of compensation contract can easily induce employees to violate the strategic objectives of bad behavior. Therefore, reasonable supervision and incentive to 
employees is also the guarantee of effective implementation of the strategy.

Based on the above analysis, this paper takes A-share listed companies from 2007 to 2019 as the sample to empirically test the impact of enterprise strategic typologies on pay gap. This results find that compared with defenders, prospectors have higher pay gap, which is more significant in enterprises with lower labor intensity. In addition, this result also reveal that the pay gap is a completely mediating variable of strategy influence on employee turnover rate. The empirical results show that according to the tournament theory, prospectors encourage employees to work hard in order to obtain competition prize through higher pay gap. Employees' compensation is also affected by the negotiation strength between management and employees, that is, the relative importance of labor force. When the labor intensity is high and employees have relative advantage in negotiation, there is no significant difference in the average compensation among employees of different strategic typologies of enterprises; If the labor intensity is low and the bargaining power of employees is weakened, the pay gap of prospectors will be significantly higher than that of defenders. The negative effect of tournament theory is that the higher pay gap destroys employees' cognition of pay equity in prospectors, and thus increases the turnover rate of employees.

This study makes several contributions to literature. Firstly, from the perspective of employees, this paper studies the impact of strategy on compensation contract, and finds that the prospectors improve the pay gap, which is a supplement and expansion to the existing literature. Secondly, it is found that labor intensity plays a moderating role in the relationship between strategy and employee compensation contracts, which provide an example for the judgment that employees of enterprises with low relative importance of labor are more likely to be at a disadvantage in wage negotiations with the management. Thirdly, with the support of large sample data, this paper analyzes the relationship between strategy and employee turnover rate, and finds that pay gap is the mediating variables.

\section{Related Literature}

Chandler (1962) [3] defined strategy as determining the long-term basic goals of an enterprise and the action guidelines and resource allocation that must be adopted to implement these goals. According to the typical characteristics of enterprises in the market competition, early literatures put forward a variety of classifications of strategic typology, two of which are often mentioned in the follow-up research, one is Prospectors, Defenders, and Analyzers [4], the other is product differentiation and cost leadership [5]. This paper selects the strategy typology of miles et al. (1978) [4], because there are similarities between prospectors and product differentiation strategy, defenders and cost leadership strategy. In addition, the strategy typology of miles can be measured by archival data [6], while other strategic typologies are more likely to use interviews or surveys to collect data in a small range, and the sample size is small. In the strategic typologies of miles et al. (1978) [4], the difference between the prospector and the defender is obvious, while the analyzers has both characteristics.

Different strategic typologies reflect different forms of enterprises to adapt to market competition or challenges. According to miles et al. (1978) [4], defenders often choose a relatively stable market area and take effective actions, such as setting competitive prices or providing high-quality products and services, to actively prevent subsequent competitors from entering this area. The organizational structure adopts the hierarchical management system with clear division of labor and centralized control, and the internal promotion opportunities are widespread. The business task of the enterprise is to improve the operation efficiency and control the product cost as much as possible. At the same time, it will develop some products to keep the growth of the enterprise. Because of relying on the single market to survive, the risk of defenders is reflected in the decline of efficiency and the inability to cope with major changes in the market environment. The characteristics of prospectors are constantly finding new market opportunities, carrying out product innovation, and systematically combining entering new fields with shrinking original fields to obtain growth opportunities. Compared with defenders, prospectors need to be more sensitive to the uncertainty of the environment, keep flexible in technology, take the problem as the orientation, and cultivate the creativity of employees, so as to make rapid response to the changing fields. Employees in key positions can be employed externally or promoted internally. Top management adopts decentralized management to deploy and coordinate resources among many decentralized divisions and projects. Technological innovation is an important tool for prospector s to keep competitive advantage, but it also faces the risk of low profit margin and abuse of resources.

Enterprise strategy can be divided into several elements, such as technology, sales, compensation, etc. the coordination of these elements in the overall strategy of the enterprise is an implicit goal of the enterprise, that is, the strategy must follow the internal consistency. This means that if the functional strategy, such as employee compensation, is not integrated or consistent with the overall strategy, the enterprise may lose its clear strategic direction, leading to suboptimal results. According to the contingency theory, there is no compensation system that is completely applicable to all enterprises, and the employee compensation contract that matches the typology of enterprise strategy may be more effective. From the perspective of strategic characteristics, the internal structure, process, technology and management of enterprises are different due to strategy typology, so strategy typology will also affect the type and degree of discretion that employees can obtain in the process of strategy implementation. Therefore, the matching degree of compensation contract and strategy typology determines whether the compensation can effectively perform the task of motivating and supervising employees. 


\section{Hypothesis Development}

\subsection{Strategy and Pay Gap}

In the listed companies with the separation of owner rights and control rights, because they cannot sign a complete contract, the management actually holds the residual control right of the enterprise. However, employee behavior will also affect the effect of strategy implementation. Whether management decisions can be implemented efficiently depends on the cooperation enthusiasm of employees. There are two levels of agency relationship in the chain of principal-agent. The first layer exists between the shareholders and the management. In order to complete the tasks entrusted by the shareholders, the management, as the agent, must employ the employees to undertake the specific work, forming the second layer agency relationship of the management as the principal. Therefore, the management also faces the problem of encouraging and supervising the employees. Compensation is the reward that the management gives the employees to take responsibility and work hard. How to design the compensation contract to motivate them to implement the strategy more effectively?

There are two problems to be solved. First of all, there is the problem of information asymmetry between the management and the employees, which is easy to lead to moral hazard. That is to say, the employees know more about their own ability, work effort and the impact of the external environment on labor productivity than the management. When the employees who are in the information advantage side execute the contract, they will not be able to realize the moral hazard, Employees may reduce their work effort or take actions that are beneficial to themselves but harm the interests of management, and they will not bear all the consequences. Compared with defenders, the process of project decision-making and technological innovation of prospectors is not easy to be programmed, the uncertainty between behavior and result is higher, the possibility of moral hazard of employees is greater, and the cost and difficulty of compensation supervision will also increase.

Secondly, the human capital of employees belongs to specific assets. After they are employed in an enterprise, they can't follow the example of shareholders to diversify their risks. Therefore, their behavior may be more conservative than the management hopes, and they are negligent in the implementation of valuable but high-risk projects. Prospectors is easy to bring bankruptcy risk to the enterprise when the business performance is poor, which makes the employees lose their jobs and damages the value of their human capital. Therefore, from the perspective of agents, employees themselves are reluctant to implement higher risk strategies, and the result may be that employees' daily behavior is out of line with long-term strategic objectives, which damages the interests of management and shareholders.

Due to the need to constantly research and develop new technologies and new fields, the prospectors need employees to bear a higher level of risk than the defenders. As an agent, employees are risk averse. The management of prospectors need to design an effective risk-taking mechanism in the employee compensation contract to guide employees to be willing to engage in work with slightly higher risk but higher enterprise value. At the same time, in the team activities that emphasize cooperative production and task interdependence, in order to reduce the adverse impact of moral hazard, the management also needs to use the compensation contract to solve the internal free riding behavior and mobilize the enthusiasm of employees. Employees do not have the right to claim residual income and will not pursue performance as they do in their own enterprises. They may choose to be lazy between hard work and laziness. When the supervision mechanism of enterprises is reliable and the cost is low, it is the best scheme to pay based on absolute performance. However, in the case of high cost of supervision, the degree of work effort of employees cannot be identified by low cost, the benefits of laziness are obtained by individuals, but the cost of per capita output decline is shared by all members of the enterprise, and the loss of improper supervision may exceed the efficiency benefits brought by absolute performance-based pay.

Tournament theory is an incentive mechanism to solve the agency problem by comparing the relative performance. The enterprise must award the maximum reward to the most efficient employees in order to motivate their efforts. Lazear and Rosen (1981) [7] proposed that when the supervision cost of effort and output is high, employees should be paid according to their internal grade rather than their absolute performance. First, relative performance may be easier to assess than absolute performance. If we don't compare with others, we usually can't know whether the output of employees is satisfactory. This kind of performance pay system may have better classification effect, so as to attract more high-quality employees [8]. Second, relative performance is not affected by common productivity shocks, such as recessions. When the internal and external environment of an enterprise changes, it is difficult to identify whether the employee's performance is the result of work effort, personal ability or other objective factors. It can be seen that the salary system based on relative performance can motivate employees to make more efforts and bear higher risk level, so as to obtain promotion opportunities and more abundant income.

According to tournament theory, the pay gap plays a unique role in performance incentive. The enthusiasm of employees not only depends on the level of their own pay, but also is affected by the management pay. Higher pay gap can induce low-level employees to make efforts to win competition prizes, rather than immerse themselves in past achievements [7, 9]. In the case of a large number of competitors and increasing environmental uncertainty, in order to stimulate competition participants to improve their efforts and willingness to take risks, enterprises should increase the pay gap. The result of competition is to optimize the allocation of internal resources and improve enterprise performance [10]. Prospectors are faced with greater risks and uncertainties. If they can match the higher pay gap than defenders, the competition among employees may improve the overall labor productivity.

In addition, higher pay gap can also reduce the agency cost 
of exploratory enterprises. Smith and watts (1992) [11] believe that moral hazard may be more obvious in companies with high growth opportunities, because employees have more discretion than those with low growth opportunities. For these bad behaviors, the larger the pay gap, the less need for costly supervision. As long as effective incentives are provided, the interest disputes between the principal and the agent can be better coordinated. To sum up, prospectors are more likely to attract employees to participate in the promotion tournament by increasing the pay gap, so as to alleviate the problems of supervision and risk-taking.

H1: the more aggressive the company's strategy is, the greater the pay gap is.

\subsection{Strategy, Pay Gap and Employee Turnover Rate}

Pay is an important determinant of employee behavior. Prospectors can provide more high-quality innovation output than defenders. One of the influencing paths is to provide relatively high internal pay gap to motivate managers and employees with innovative ability. However, the higher pay gap and lower employee pay in prospectors reduce team cohesion and employee satisfaction, destroy the working environment, and may therefore push up employee turnover rate.

Tournament theory holds that promotion and salary level should be based on relative performance rather than absolute performance, which leads to negative externality of individual efforts on the salary of employees at the same level. Therefore, pay gap will stimulate individual rent-seeking behavior, which may lead to employees' direct destruction of other people's activities in extreme cases [12]. Cowherd and Levine (1992) [13] found that the huge pay gap between low-level employees and top managers can lead to the feeling of inequality and relative scarcity, and reduce the desire of employees to work hard and cooperate within the team.

Bennedsen et al. (2019) [14] thinks that the mediating variables between pay and turnover are job satisfaction, organizational commitment, search behavior and willingness to stay. Satisfaction refers to employees' love of work, while organizational commitment refers to employees' loyalty to the enterprise. Search behavior refers to the possibility of employees looking for other jobs, while the intention to stay refers to the extent to which employees plan to continue to maintain an employment relationship with the enterprise. Employees bring personal expectations into the workplace. If these expectations are met, employees will be satisfied and promise to stay in the company. Both equity theory and social comparison theory believe that employees will compare their contribution level and pay with those of the same level, and they will feel fair only when their contribution level matches with their pay [15]. Pay equity includes distributive equity, procedural equity and interactive equity, among which distributive equity, interactive equity and organizational commitment are significantly related.

The employee compensation contract of prospectors not only easily destroys the team cooperation atmosphere, but also attacks the willingness of employees to obtain ideal return through labor. These negative factors of organizational commitment push up the turnover intention. High quality employees with turnover intention are more likely to put the idea of leaving the company into action, because they have the ability to search for other satisfactory jobs. In addition, the prospectors have the characteristics of constantly trying new technologies, entering or exiting some fields, which will also lead to some bottom employees have to leave passively and lose their jobs. In conclusion, the prospectors may lead to employee turnover more easily than the defenders.

H2: Prospectors will raise the turnover rate by increasing the pay gap.

\subsection{Strategy, Labor Intensity and Pay Gap}

Employee compensation contract is the main content of communication in the agency relationship between management and employees. Its formation process is not only subject to the enterprise incentive and supervision mechanism, but also affected by the bargaining power between management and employees. In addition to labor supply and demand, labor attributes and labor system protection, the direction of technological progress of enterprises will also affect the long-term bargaining power between management and employees. The endogenous growth theory of technological progress represented discusses the influence mechanism of factor price on the direction of technological progress [16]. Because the cost of scarce factors is higher, the price effect will lead the direction of technology to prefer to save relatively scarce production factors. In practice, employees' expectation of salary gradually increases with time which reduces the relative price of capital and labor. The less labor-intensive enterprises rely on labor, the less important the employees are, and the more flexible the management is, the less bargaining power the employees will have. Correspondingly, in order to prevent employees from leaving and ensure the labor demand of the enterprise, the management has the motivation to provide employees with higher salary. Therefore, in the group with lower bargaining power, the result of labor negotiation is more unfavorable to employees, and they are more likely to be forced to accept lower salary. The significance of the above hypothesis is more likely to focus on enterprises with lower labor intensity.

H3: The more radical the strategy is, the larger the pay gap is, which is more likely to appear in enterprises with lower labor intensity.

\section{Sample Selection, Variables and Descriptive Statistics}

This paper uses the data of Chinese A-share listed companies from 2007 to 2019 as the research sample, and all the data are from CSMAR database. The samples put in order according to the following procedures:(1) the samples of Listed Companies in the financial industry were excluded, (2) the samples with missing related variables were excluded, (3) the samples with asset liability ratio greater than one are excluded. In order to avoid the influence of extreme values, all 
continuous variables are winsorized at the top and bottom $1 \%$ of the distribution. After the above steps, 14,606 observations were obtained.

\subsection{Strategy}

Consistent with Bentley et al. (2013) [6], This paper constructs Strategy variables according to the following six dimensions: (1) the average proportion of intangible assets in total assets in the past five years $(R D),(2)$ the average growth rate of operating revenue in the past five years $(R E V),(3)$ the average proportion of sales expenses and management expenses in operating revenue in the past five years $(S E M)$, (4) the average proportion of fixed assets in total assets in the past five years (PPE), (5) Average number of employees as a proportion of operating revenue in the past five years (EMPS) (6) the ratio of the standard deviation of the number of employees to the average number of employees in the past five years $(E M P)$.

$R D$ measure the importance of $R \& D$ to enterprises, $R \& D$ is the most important activity of prospector. When $R D$ are used to reflect the strategy typology, the score of prospector is higher.

$R E V$ measures the growth of enterprises; SEM measures the efficiency of the use of costs. Defender need to make profits from the single market and pay more attention to efficiency and cost control; prospector achieve growth through product innovation and market expansion, and there is a risk of resource abuse. It can be seen that the growth of prospector and the cost of sales and management per unit of income are significantly higher than that of defender, and prospector should get a higher score in the two dimensions of $R E V$ and $S E M$.

$P P E$ measure the degree of enterprise mechanization. The organizational structure of prospector is unstable, and by maintaining a low proportion of fixed assets, excessive investment in a single technology can be avoided; Defender have a stable market and attach importance to production, which requires a lot of investment in order to improve the efficiency of core technology. In this dimension, defender should get a higher score.

EMPS measure the ability of producing and distributing its products and services effectively, the higher the score is, the lower the enterprise's effective operation ability is; EMP measure employee volatility. In order to ensure efficiency, defenders attach great importance to production activities. They not only choose a centralized control organizational structure, but also try to maintain a stable staff team. Therefore, employees tend to have long tenure and more internal promotion opportunities. On the contrary, due to the needs of technological innovation and market development, at the expense of the efficient operation ability of production and distribution process, prospector have a higher frequency of organizational structure adjustment, which also results in higher employee volatility. Therefore, prospector should get higher score in the two dimensions of EMPS and EMP.

According to the industry and year grouping, the above dimensions are divided into five equal parts, and assigned to 5 , 4, 3, 2 and 1 respectively according to the value from large to small, in which the reverse assignment is required. Taking each enterprise-year as a unit, the enterprise's Strategy is obtained by summing up the corresponding scores of the above indicators, and the score range is between 6 and 30. The higher the score of Strategy is, the more likely the enterprise is to be prospector. The smaller the score, the more likely the enterprise is to be defenders.

\subsection{Pay Gap}

Gap is defined as the natural logarithm of the ratio of the average salary of the management and the average salary of the employees.

\subsection{Employee Turnover Rate}

ETR is measured by the change rate of the number of employees in two adjacent periods.

\subsection{Control Variable}

This paper also controls the following variables: Size, $L E V$, ROA, MTB, Risk, Age, Bsize, Top1, Indep, Dual, Hold, SOE, $G D P$. In addition, dummy variables of industry, year and province are also included in the model to control the fixed effect of industry and year. Specific variable definitions are shown in Table 1.

Table 1. Variable definitions.

\begin{tabular}{ll}
\hline Variable & Definition \\
\hline Strategy & The total score of six dimensions ranges from 6 to 30 \\
Gap & Divide the average salary of the management by the average salary of the employees, and then take the natural logarithm \\
Size & Natural logarithm of company's total asset \\
Lev & Asset liability ratio \\
ROA & Return on total assets \\
Risk & Stock market value at the end of the year divided by book value of owner's equity \\
MTB & The company's market value at the end of t year divided by the book value of net assets \\
Age & Taking the natural logarithm after subtracting the listing year of the company from the current year \\
Bsize & Natural logarithm of the number of directors \\
Top1 & Shareholding ratio of the largest shareholder \\
Indep & Number of Independent Directors divided by number of directors \\
Dual & When the chairman of the board concurrently serves as the general manager, it is equal to one, otherwise it is equal to zero \\
Hold & number of shares held by senior executives divided by the total number of shares \\
SOE & If the company is a state-owned enterprise, it is equal to 1, otherwise it is equal to 0 \\
GDP & GDP growth rate of the provinces where the listed companies are located \\
Dum & When the ratio of employees to fixed assets is greater than the annual median of the industry, it is equal to 1, otherwise it is equal to 0 \\
ETR & (number of employees in t year - number of employees in t+1 year) / number of employees in t year \\
\hline
\end{tabular}




\subsection{Descriptive Statistics}

Table 2 provides the descriptive statistical results of the main variables. The standard deviation of Gap is large, which indicates that there is a large difference between different enterprises. The median of Strategy is 18 , and the mean is 17.799, which indicates that more enterprises choose the analyzers, and the standard deviation is 4.108 , which indicates that there are great differences in the strategies typology among enterprises. The mean and median of employee turnover rate are both negative, indicating that the number of employees in nearly half of the company's years is on the rise, and the number of employed people is increasing. The standard deviation is 0.572 , indicating that there is a large difference between the years.

Table 2. Summary statistics.

\begin{tabular}{|c|c|c|c|c|c|c|}
\hline Variable & $\mathbf{N}$ & Mean & SD & Min & Median & Max \\
\hline $\operatorname{Gap}_{\mathrm{i}, \mathrm{t}+1}$ & 14606 & 1.279 & 0.718 & -0.997 & 1.270 & 3.100 \\
\hline Strategy & 14606 & 17.799 & 4.108 & 9 & 18 & 27 \\
\hline Size & 14606 & 22.271 & 1.283 & 19.400 & 22.100 & 26.100 \\
\hline ROA & 14606 & 0.035 & 0.054 & -0.213 & 0.031 & 0.199 \\
\hline Risk & 14606 & 0.352 & 2.490 & 0.005 & 0.028 & 22.500 \\
\hline MTB & 14606 & 3.883 & 3.697 & 0.603 & 2.820 & 25.900 \\
\hline Bsize & 14606 & 2.168 & 0.203 & 1.610 & 2.200 & 2.710 \\
\hline Top1 & 14606 & 34.932 & 15.150 & 8.450 & 33 & 75 \\
\hline Indep & 14606 & 0.370 & 0.053 & 0.300 & 0.333 & 0.571 \\
\hline Dual & 14606 & 0.179 & 0.383 & 0 & 0 & 1 \\
\hline Hold & 14606 & 22.721 & 73.112 & 0 & 0.019 & 437 \\
\hline SOE & 14606 & 0.557 & 0.497 & 0 & 1 & 1 \\
\hline GDP & 14606 & 0.116 & 0.053 & 0.003 & 0.104 & 0.249 \\
\hline $\mathrm{ETR}_{\mathrm{i}, \mathrm{t}+2}$ & 12468 & -0.114 & 0.572 & -4.560 & -0.007 & 0.624 \\
\hline
\end{tabular}

\section{Empirical Results}

This paper establishes a regression model (1) in order to study the relationship between strategy and pay gap. In order to alleviate the possible, endogenous problems such as reverse causality to a certain extent, Strategy and control variables in the model lag one period. According to this rule, ETR should be advanced one year compared with Gap, that is, in year $t+2$. model (1), (2), (3) are used to test the influence path between strategy and employee turnover rate, Gap is a mediating variable. The results of empirical regression are shown in Table 3.

$$
\begin{aligned}
& \operatorname{Gap}_{i, t+1}=\alpha_{0}+\alpha_{1} \text { Stragety }_{i, t}+\text { Controls }_{i, t}+\text { industry }+ \text { year }+ \text { province }+\varepsilon_{i, t} \\
& \text { ETR }_{i, t+2}=\alpha_{0}+\alpha_{1} \text { Stragety }_{i, t}+\text { Controls }_{i, t}+\text { industry }+ \text { year }+ \text { province }+\varepsilon_{i, t} \\
& \text { ETR }_{i, t+2}=\alpha_{0}+\alpha_{1} \text { Stragety }_{i, t}+\alpha_{2} \text { Gap }_{i, t+1}+\text { Controls }_{i, t}+\text { industry }+ \text { year }+ \text { province }+\varepsilon_{i, t}
\end{aligned}
$$

\begin{tabular}{|c|c|c|c|c|c|}
\hline & (1) & (2) & (3) & (4) & (5) \\
\hline & \multirow{2}{*}{$\operatorname{Gap}_{i, t+1}$} & \multirow{2}{*}{$E T R_{i, t+2}$} & \multirow{2}{*}{$E T R_{i, t+2}$} & \multicolumn{2}{|c|}{$\operatorname{Gap}_{i, t+1}$} \\
\hline & & & & Dum $=1$ & Dum $=0$ \\
\hline \multirow[t]{2}{*}{ Strategy } & $0.024 * * *$ & $0.013 * * *$ & 0.004 & 0.006 & $0.012 * * *$ \\
\hline & $(7.55)$ & $(4.70)$ & (1.53) & $(1.24)$ & $(3.16)$ \\
\hline $\operatorname{Gap}_{i, t+1}$ & & & $0.366 * * *$ & & \\
\hline & & & $(15.80)$ & & \\
\hline Control Variables & Yes & Yes & Yes & Yes & Yes \\
\hline industry & Yes & Yes & Yes & Yes & Yes \\
\hline year & Yes & Yes & Yes & Yes & Yes \\
\hline $\mathrm{N}$ & 14,606 & 14,606 & 14,606 & 7,254 & 7,352 \\
\hline Adjust. R-Square & 0.06 & 0.03 & 0.10 & 0.05 & 0.07 \\
\hline
\end{tabular}

Table 3. The effect of strategy, pay gap and employee turnover rate.

$* * *, * *$, and $*$ indicate that the $t$ statistic is statistically significant at the 1,5 , and $10 \%$ levels, respectively. All the standard errors of regression coefficients in this paper are processed by cluster at the enterprise level.

Column (1) of Table 3 reports the impact of strategy on pay gap. The coefficients are all positive and significant at the $1 \%$ level, that is, the more aggressive the strategy is, the larger the pay gap is, which is consistent with H1. Column (2) is the result of model (2), and the sign of Strategy is significantly positive, which indicates that the more aggressive the enterprise strategy is, the higher the employee turnover rate is. Column (3) is the result of the model (3). The coefficient of the mediating variables $\left(G a p_{i, t+1}\right)$ is significantly positive at the $1 \%$ level, while the coefficient of Strategy is no longer significant, and the coefficient and $t$ value are less than those in column (2), indicating that the pay gap is a complete mediating variable between strategy and employee turnover rate, consistent with $\mathrm{H} 2$. According to the annual median of labor intensity, this paper divides the sample into two groups: high and low labor intensity, and uses the model (1) regression. The results are reported in columns (4) and (5). The coefficient of Strategy in the high density group was not significant, while the coefficient of Strategy in the low density group was significantly positive at the $1 \%$ level. The above 
phenomenon is consistent with $\mathrm{H} 3$.

\section{Conclusion}

This paper examines the impact of strategy on compensation contract from the perspective of employees, and selects the data of Chinese A-share listed companies from 2007 to 2019 as the research sample. The empirical results show that compared with defenders, prospectors have higher pay gap, which is more significant in enterprises with lower labor intensity. Prospectors also increase the turnover rate of employees, because the higher pay gap destroys employees' perception of pay equity.

The pay gap is the driving force to encourage innovation, but when the pay gap widens, there will be corresponding negative problems. Therefore, enterprises should keep the pay gap within a reasonable range to maintain the relative fairness of pay. If stakeholder hope to stimulate the vitality of enterprises and keep the economy basically good, and also hope to reduce the turnover rate and maintain social stability, they should also make institutional guarantee for integrating innovative resources and promoting employment. When employees have low skills, they are not likely to work harder, because they realize that they do not have the technical or management skills required for high-level positions, which weakens the incentive effect of pay gap. It is a valuable suggestion to implement the public policy of increasing investment in vocational training and helping employees improve their skills.

\section{References}

[1] Simons R. (1987). Accounting Control Systems and Business Strategy: an Empirical Analysis. Accounting, Organizations and Society, 12 (4): 357-374.

[2] Singh P, Agarwal N C. (2002). The Effects of Firm Strategy on the Level and Structure of Executive Compensation. Canadian Journal of Administrative Sciences, 19 (1): 42-56.

[3] Chandler A D. (1962). Strategy and Structure: Chapters in the History of the Industrial Enterprise. MIT Press.
[4] Miles R E, Snow C C, Meyer A D, Coleman H J. (1978). Organizational Strategy, Structure, and Process. Academy of Management Review, 3 (3): 546-562.

[5] Porter M E. (1980). Competitive strategy: Techniques for Analyzing Industries and Competitors. New York: The Free Press.

[6] Bentley K A, Omer T C, Sharp N Y. (2013). Business Strategy, Financial Reporting Irregularities, and Audit Effort. Contemporary Accounting Research, 30 (2): 780-817.

[7] Lazear E P, Rosen S. (1981). Rank-Order Tournaments as Optimum Labor Contracts. Journal of Political Economy, 89 (5): 841-864.

[8] Lazear, Edward P. (2000). Performance Pay and Productivity. American Economic Review, 90 (5): 1346-1361.

[9] Chi W, Liao H, Wang L, Zhao R, Ye Q. (2019). Incentives to Move Up: Effects of Pay Gaps between Levels on Employee Performance [J]. Human Resource Management Journal, 29 (2): 238-253.

[10] Faleye O, Reis E, Venkateswaran A. (2013). The Determinants and Effects of CEO-Employee Pay Ratios [J]. Journal of Banking \& Finance, 37 (8): 3258-3272.

[11] Smith Jr C W, Watts R L. (1992). The Investment Opportunity Set and Corporate Financing, Dividend, and Compensation Policies. Journal of financial Economics, 32 (3): 263-292.

[12] Feldman E R, Gartenberg C, Wulf J. (2018). Pay Inequality and Corporate Divestitures [J]. Strategic Management Journal, 39 (11): 2829-2858.

[13] Cowherd D M, Levine D I. (1992). Product Quality and Pay Equity Between Lower-Level Employees and Top Management: An Investigation of Distributive Justice Theory. Administrative Science Quarterly, 37 (2): 302-320.

[14] Bennedsen M, Tsoutsoura M, Wolfenzon D. (2019). Drivers of Effort: Evidence from Employee Absenteeism [J]. Journal of Financial Economics, 133 (3): 658-684.

[15] Cascio W F, Chatrath A, Christie-David R A. (2021). Antecedents and Consequences of Employee and Asset Restructuring [J]. Academy of Management Journal, 64 (2): 587-613.

[16] Kemp-Benedict E. (2019). Cost Share-induced Technological Change and Kaldor's Stylized Facts [J]. Metroeconomica, 70 (1): 2-23. 